\title{
Evaluation of Collision Potential at Four- Legged Unsignalized Intersection Using Traffic Conflict Technique
}

\author{
Biliyamin A. Ibitoye, Rasheed AbdulWahab and Abigael Bamidele
}

\begin{abstract}
The counting of traffic conflict allows the estimation of accident potential at a particular location such as at-grade intersection. The objective of this paper is to examine the evasive action of driver occurs with some frequency at Shao intersection which may result in potential accident. This paper applied traffic conflict techniques to evaluate collision potential at unsignalized intersection located at Shao. The morning and evening peak traffic flow was captured using a video camera for seven days and then analyzed by playing back the video on daily basis. The 100 sample size of observed conflict was based on $95 \%$ confidence level, $5 \%$ permitted error and the proportion of the vehicles that were involved in a specific conflict for the observed traffic flow. The conflicts identified were compared with volume counts at minor approach. The daily peak hour approach traffic volumes were found to have a close relationship with the percentage values of conflict on the two minor approaches. It also showed that rear end collision accounted for more than $\mathbf{7 0}$ percent of traffic conflicts and it correlated well with the traffic volumes on WB and EB approaches.
\end{abstract}

Index Terms-Accident Record; Conflict Study; Peak Traffic Flow; Unsignalized Intersection.

\section{INTRODUCTION}

Accident potential exists at any location where evasive action of driver occurs with some frequency as exist at the study location. On consulting the Federal Road Safety Corps, Zone RS 8.1.5 - Oloru Unit Command, it was observed that very few accidents were reported for the past five years at study intersection despite frequency of accident recorded by the host community. Many studies indicated that under-reporting and accuracy problems of accident data is significant due to incomplete and inconsistent reporting [1],[2] . Thus, this warrants using Conflict Study Method as alternative investigation method to evaluate collision potential at the intersection. Transport Road Research Laboratory (TRRL) defines a traffic conflict as an observable situation in which two or more road users approach each other in time and space to such an extent that there is risk of collision if their movements remain unchanged [3],[4]. This definition explains what exist at the study area. Traffic conflicts mean a situation where road

Published on March 10, 2017

B.A. Ibitoye is with the Kwara State Univrsity, Malete, PMB 1530 Ilorin Nigeria (e-mail: biliyamin.ibitoye@ Kwasu.edu.ng).

R. AbdulWahab is with Kwara State Univrsity, Malete, PMB 1530 Ilorin Nigeria (e-mail: Rasheed.abdulwahab@ Kwasu.edu.ng).

A. Bamidele is with Kwara State Univrsity, Malete, PMB 1530 Ilorin Nigeria. She is a graduate currently on national service (NYSC) in Jigawa State. users violate the traffic rule to cause other road users to do a runaway manoeuvre to prevent a conflict. This runaway manoeuvre can be a sudden brake, sudden line change, etc [5].

Although measures based on proximity play an important role in traffic conflict techniques, no consensus has yet been reached on what measures should be given preference [6].

Diversity in nature and applications of the various measures limits their uses to estimation of crash risks and thus, the combined use of various measures has been suggested [7]. Therefore, it is difficult to distinguish the consequences, in terms of severity, when all traffic events in a safety continuum are considered [8]. Most traffic flow on the major approach consists of heavy vehicle travelling at high speed leaving the traffic on the minor approach in dilemma of looking for gap. Traffic on major approach connect heavy vehicles from south west to the northern part of Nigeria while the minor approach traffic consisting of public and private cars and buses only serves commuters from Ilorin town to Malete where Kwara State university is located.

Assertions from earlier studies indicated that most traffic conflicts at unsignalized intersections are due to left turn. Left turn in unsignalized intersections, especially from minor street to major street creates many problems and increases conflicts, which is a great factor for accidents [9]. This situation may create many problems and increased conflicts, which could be a great factor for a serious or fatal accidents at the intersection. Therefore, traffic conflict study involves observation of traffic events such as near misses, sudden stopping, and swerving to avoid rear-end collisions were often noted and sometimes documented [10].

Conflicts and events are most often quantified in terms of units of conflicts per hour or conflicts per 1,000 entering vehicles [11]. In this study, conflicts are quantified in terms of units of conflict per peak hour. In view of only few crash data reported by the Federal Road Safety Corps for the study intersection which are not reliable for accident analysis, conflict study was carried out. Data of vehicle conflicts were collected and presented in terms of their numbers and types. This agrees with the study from [11]; which confirmed that in the absence of reliable crash data, or when there is no data at all, traffic conflict techniques can be applied effectively to evaluate traffic safety at four- legged signalized intersections. In 1985, many researches and studies were launched and indicated that some certain types of traffic conflict probabilities in intersections are related to each other. It means that conflict probabilities may be considered as a proper substitute for conflict statistics in 
analysis of roads and intersection safety [12]. Also in 1992 salesman studied eight unsignalized intersection and indicated that square of approach volume may well define the relation between conflict and traffic volume [13].

\section{DESCRIPTION OF STUDY AREA}

The study area is located at Shao at an elevation of 269 meter above sea level and its coordinates are $8^{\circ} 34^{\prime} 60^{\prime \prime} \mathrm{N}$ and $4^{\circ} 34^{\prime} 0$ ', E. The area is $7 \mathrm{~km}$ from Ilorin city, the north central of Nigeria. It consists of four-leg unsignalized intersections connecting traffic from Ilorin (Kwara State Capity City) on West Bound approach to Malete (14 km away) on East Bound approach. The major approach which is $4 \mathrm{~km}$ from end of Ogbomosho - Ilorin Expressway at Oko-Olowo connects heavy vehicles traffic coming from Lagos to the north.

There are some existing activities at the intersection. Such activities include petrol station and Motor Park, Market and erection of various sign posts/bill boards along the East and West bond of the minor approaches respectively (Fig. 1 and 2 ). These activities constitute distractions, obstructions to sight and lateral clearance for crossing traffic and thereby creating potential conflict for vehicle and pedestrian crossing the major road from the minor approaches. The observed damages along the shoulder which result in reduced lane width could also lead to increase potential collision at this intersection (Fig. 2).

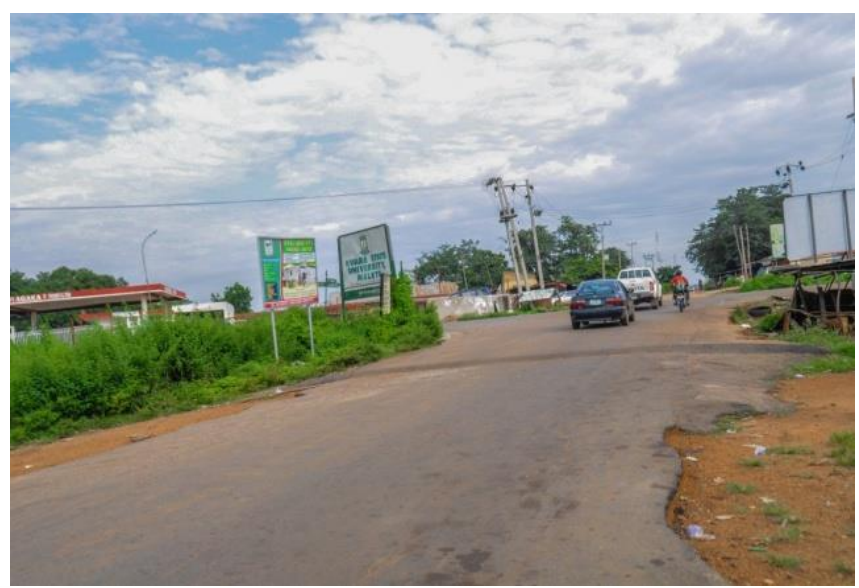

a) Billboard obstructing Sight

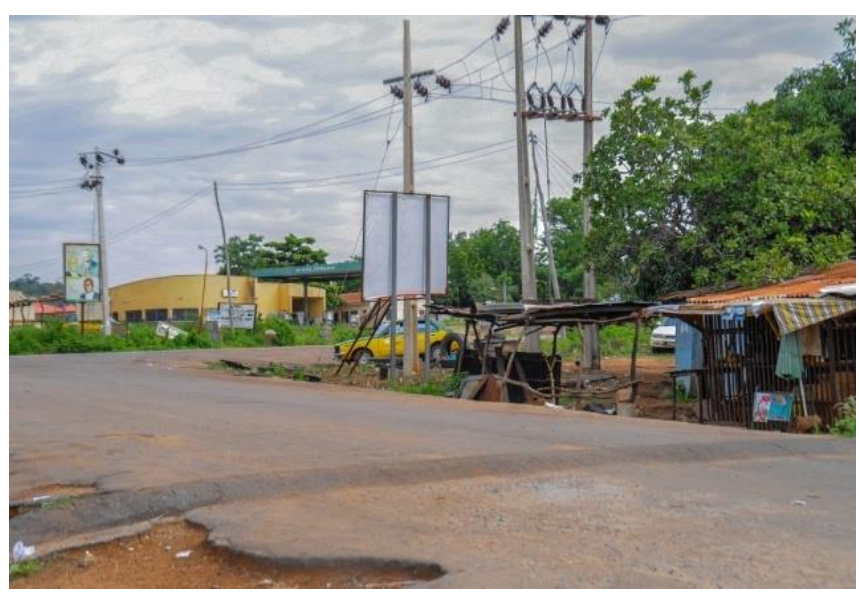

b) Market activity endangering lives

Fig. 1. Activities at minor approaches of Intersection $(a, b)$

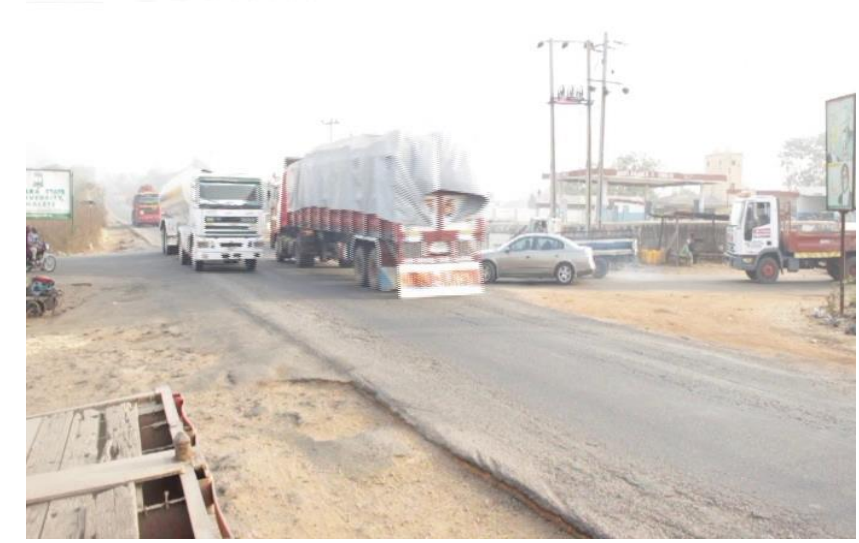

Fig. 2. Effect of lane width reduction on major road with heavy traffic.

\section{ReSEARCh Methodology}

\section{A. Data Collection}

In general, the major task was to videotape the traffic flow at intersection with the aim of collecting necessary data and assess the safety of the intersection. The physical characteristics of the intersection were also recorded during data collection as a supplement to the study.

The conflict field study was performed during morning and evening peak periods of traffic. Based on the initial study on the frequency of traffic flow on this route, the two hours morning and evening peak periods between 8.00am $10.00 \mathrm{am}$ and $3.00 \mathrm{pm}-5.00 \mathrm{pm}$ were considered respectively. The study was carried out for seven consecutive days (Monday to Sunday); capturing both traffic conflict and volume. The route is dominated by the traffic flow of vehicles (private and public cars) carrying students and staff of Kwara State University Malete. The university is located $14 \mathrm{~km}$ away from the study area which falls along the minor approach of the intersection. The major approaches are dominated with heavy truck traffic (see Fig. 2)

In addition, five (5) years reported accident data on the intersection were collected from the Federal Road Safety Corps, Zone RS 8.1.5 - Oloru Unit Command. Also, activities within the intersection and drivers' behaviour such as emergency stopping at road edge, sounding of horns, sudden swerving and anticipated breaking were recorded.

\section{B. Sample size requirement}

The following equation 1 below (Box and Oppenlander, 1976) was used to determine the minimum number of counts (sample size) that were taken for each movement of each type of conflict that were checked in the study:

$$
N=\frac{\mathrm{pqK}^{2}}{\mathrm{E}^{2}}
$$

Where $\mathrm{N}=$ minimum sample size

$\mathrm{p}, \mathrm{q}=$ proportion of vehicles that are involved in a specific traffic conflict for the observed flow of traffic

$\mathrm{K}=$ constant corresponding to the desired confidence level

$\mathrm{E}=$ permitted error in the proportion estimate of traffic conflicts 
The sum of $\mathrm{p}$ and $\mathrm{q}$ is always equal to 1.0. The constant $\mathrm{K}$ depends on the desired level of confidence which indicates the probability that the proportion of a specific traffic conflict is a valid estimate. The permitted error E in the estimate of proportions is based on the precision that is required in the study.

Assuming 95.0\% confidence level giving $\mathrm{K}$ value $=1.98$, 10 percent maximum error and proportion of vehicle that are involved in specific conflict for the observed flow of traffic $\mathrm{p}=0.3$ and $\mathrm{q}=0.7$, the minimum sample size was determined as 82 conflicts. Thus, 100 samples were collected in this study (Table IV).

\section{Evasive Action by Drivers}

The recorded video of traffic movement at the intersection was played back and the numbers of conflicts were read and recorded at the end of every 15- minute interval. The evasive action by drivers to avoid collisions which is the number of actual traffic conflicts as well as traffic violations and the volumes for the direction of approach were counted. The evasive action of drivers is evidenced by a brake light indication or lane change. The observed traffic conflicts are in form of left-turn from wrong lane, opposing left turn, turn into wrong lane, stop-on-lane or lane change to avoid collision (near missed situation), sudden braking or violent swerving off road (very near missed situation) and dangerous crossing on heavy vehicle horning. Thus, most of them can be classified as serious conflict.

\section{RESUlts AND Discussion}

\section{A. Analysis of Reported 5-year accident data}

The accident data reported by FRSC for five years' record is presented in Table I. A severity analysis of the accident was first calculated to evaluate the seriousness of accident occurring at this intersection. Severity Index can be defined as the number of deaths per 100 accidents occurring at an intersection (Parker and Zegeer, 1989a). It was then calculated by the following formula:

$$
\text { Severity Index }=\frac{\text { Fatal Accidents }}{\text { All Accidents }} \times 100
$$

Using (2) for Table I, thirty-one (31\%) percent severity index was obtained. This indicates that the study intersection is an accident prone area that requires checks on collision potential and lack of adequate accident data warrants the use of alternative technique called traffic conflict technique to evaluate crash events at this intersection.

\begin{tabular}{|c|c|c|c|c|c|c|c|}
\hline Date & Year & RTC Type & $\begin{array}{c}\text { No of } \\
\text { Vehicle } \\
\text { Involved }\end{array}$ & Type of Vehicle & $\begin{array}{c}\text { No of } \\
\text { People } \\
\text { Involved }\end{array}$ & $\begin{array}{l}\text { No of } \\
\text { People } \\
\text { Injured }\end{array}$ & $\begin{array}{l}\text { No of } \\
\text { People } \\
\text { Killed }\end{array}$ \\
\hline 11/03/2011 & \multirow{2}{*}{2011} & Serious & 3 & Truck/Car/MC & 13 & 2 & 0 \\
\hline 17/05/2011 & & Minor & 2 & Car/Truck & 8 & 0 & 0 \\
\hline $2 / 04 / 2012$ & 2012 & Serious & 2 & Car/Car & 10 & 1 & 0 \\
\hline $15 / 10 / 2013$ & \multirow{2}{*}{2013} & Serious & 2 & Car/Car & 5 & 3 & 0 \\
\hline 27/10/2013 & & Serious & 1 & Truck & 2 & 2 & 0 \\
\hline $16 / 04 / 2014$ & \multirow{2}{*}{2014} & Fatal & 1 & Car & 13 & 3 & 2 \\
\hline $21 / 07 / 2014$ & & Fatal & 2 & Car/Truck & 6 & 5 & 1 \\
\hline $20 / 03 / 2015$ & \multirow{2}{*}{2015} & Serious & 1 & Car & 6 & 3 & 0 \\
\hline $26 / 03 / 2015$ & & Fatal & 2 & Car/Truck & 6 & 2 & 2 \\
\hline & OTAL & & 16 & & 69 & 21 & 5 \\
\hline
\end{tabular}

\section{B. Analysis of Intersection Traffic Movement}

Table II and Table III illustrate traffic movement at the intersection during morning and evening peak respectively. The traffic flow along the minor approaches; from West Bound in the morning and from East Bound in the evening are very important to this study as the approaches commune daily traffic to and from Kwara State University. Thus, the average number of vehicles likely to involve in conflict with vehicles daily along minor approaches are 132 vehicles in the morning peak and 91 vehicles during the evening peak. This implies that average of 112 vehicles will likely involve in conflicts daily. Therefore, the collection of 100 conflicts in this study is very adequate as it falls within the permitted error.

TABLE II: AVERAGE PEAK HOUR MORNING TRAFFIC FlOW

\begin{tabular}{lccccccccccccccccc}
\hline \multicolumn{10}{c}{ TABLE II: AVERAGE PEAK HOUR MORNING TRAFFIC FLOW } \\
\hline DAY & R & TH & L & Tot. & R & TH & L & Tot. & R & TH & L & Tot. & R & TH & L & Tot \\
\hline Mon & 5 & 49 & 20 & 74 & 5 & 123 & 45 & 173 & 37 & 137 & 6 & 180 & 5 & 34 & 1 & 40 \\
\hline Tue & 1 & 71 & 11 & 83 & 1 & 171 & 38 & 210 & 47 & 122 & 2 & 171 & 3 & 39 & 0 & 42 \\
\hline Wed & 5 & 98 & 12 & 115 & 2 & 113 & 41 & 156 & 36 & 122 & 2 & 160 & 3 & 43 & 1 & 47 \\
\hline Thur & 2 & 76 & 4 & 82 & 0 & 66 & 45 & 111 & 42 & 100 & 0 & 142 & 1 & 33 & 0 & 34 \\
\hline Frid & 5 & 79 & 13 & 97 & 1 & 86 & 52 & 139 & 34 & 98 & 5 & 137 & 2 & 46 & 3 & 51 \\
\hline Sat & 0 & 77 & 4 & 81 & 1 & 74 & 36 & 111 & 22 & 36 & 1 & 59 & 0 & 32 & 0 & 32 \\
\hline Sun & 4 & 103 & 4 & 111 & 0 & 80 & 39 & 119 & 37 & 38 & 3 & 78 & 0 & 40 & 0 & 40 \\
\hline AV. & 3 & 79 & 10 & 92 & 1 & 102 & 42 & 145 & 36 & 93 & 3 & 132 & 2 & 38 & 1 & 41 \\
\hline
\end{tabular}

TABLE III: AVERAGE PEAK HOUR EVENING TRAFFIC FLOW

\begin{tabular}{lcccccccccccccccccc}
\hline & \multicolumn{4}{c}{ NORTH- BOUND } & \multicolumn{4}{c}{ SOUTH - BOUND } & \multicolumn{3}{c}{ WEST-BOUND } \\
\hline DAY & R & TH & L & Tot. & R & TH & L & Tot. & R & TH & LT & Tot. & R & TH & LT & Tot. \\
\hline Mon & 4 & 48 & 2 & 54 & 2 & 119 & 36 & 157 & 22 & 49 & 0 & 71 & 7 & 117 & 3 & 127 \\
\hline Tue & 6 & 109 & 7 & 122 & 4 & 84 & 33 & 121 & 46 & 42 & 7 & 95 & 12 & 97 & 0 & 109 \\
\hline
\end{tabular}




\begin{tabular}{lccccccccccccccccc}
\hline Wed & 1 & 98 & 6 & 105 & 1 & 83 & 30 & 114 & 35 & 32 & 1 & 68 & 8 & 90 & 0 & 98 \\
\hline Thur & 6 & 68 & 1 & 75 & 2 & 111 & 36 & 149 & 22 & 35 & 0 & 57 & 7 & 94 & 2 & 103 \\
\hline Frid & 2 & 106 & 8 & 116 & 0 & 95 & 27 & 122 & 27 & 48 & 0 & 75 & 5 & 100 & 0 & 105 \\
\hline Sat & 1 & 117 & 4 & 122 & 5 & 58 & 26 & 89 & 15 & 39 & 0 & 54 & 2 & 41 & 3 & 46 \\
\hline Sun & 0 & 103 & 2 & 105 & 0 & 61 & 18 & 79 & 13 & 46 & 0 & 59 & 1 & 48 & 0 & 49 \\
\hline AV. & 3 & 93 & 4 & 100 & 2 & 87 & 29 & 118 & 29 & 42 & 1 & 72 & 6 & 84 & 1 & 91 \\
\hline
\end{tabular}

\section{Equations Analysis of Traffic conflicts}

Pertinent conflict situations are summarized in Table IV as the average number of conflict per hour for each day of the week. Out of 100 sample of traffic conflict observed rear end collision accounted for more than 70 percent of conflict.
The greater concentration of all conflict types occur on Monday followed by Tuesday and Friday peak hours. This indicates the rush in home-work and work-home trips on these days. Thus, the relationship between conflict and traffic volume shows good correlation for $\mathrm{WB}$ and $\mathrm{EB}$ approaches.

TABLE IV: SUMMARY OF TRAFFIC CONFLICT AT THE INTERSECTION

\begin{tabular}{lccccccccc}
\hline $\begin{array}{l}\text { Conflict Situation } \\
\text { average number per } \\
\text { peak hour) }\end{array}$ & MON & TUE & WED & THU & FRI & SAT & SUN & \multicolumn{2}{c}{$\begin{array}{c}\text { CORREL. } \\
\text { COEFF. }\end{array}$} \\
\hline Rear-End left-turn & 10 & 5 & 6 & 1 & 7 & 4 & 0 & 0.61 & 0.67 \\
\hline Rear -end thru-lane & 16 & 9 & 2 & 4 & 1 & 2 & 0 & 0.66 & 0.59 \\
\hline Swerve- off road & 4 & 1 & 1 & 1 & 2 & 2 & 0 & 0.32 & 0.45 \\
\hline Side impact & 5 & 1 & 0 & 2 & 6 & 2 & 2 & 0.11 & 0.34 \\
\hline TOTAL CONFLICT & 36 & 16 & 9 & 8 & 16 & 6 & 2 & 100 \\
\hline
\end{tabular}

\section{Analysis of Percentage value of Conflict on Minor Approaches}

Fig. 3 presents the percentage values of conflict as the number of traffic conflict expressed as the ratio of the crossing traffic volume count on WB and EB for the traffic situation along minor approaches. The close relationship implies that traffic movement on WB correspond to EB as most vehicles along this road returns to Ilorin daily.

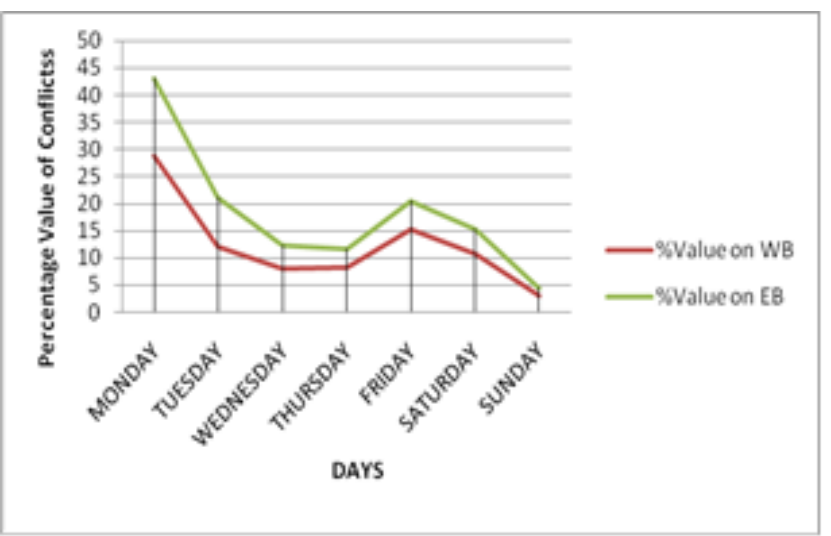

Fig. 3. Percentage Values of Conflict on WB and EB Approaches.

\section{CONCLUSION}

This study has demonstrated the potential conflict that may lead to serious accidents at the intersection. The major concern is the traffic problem arising as the population of vehicles and economic activities are increasing significantly at this intersection. This problem has been considered as the biggest problem facing all commuters along Ilorin to Malete while crossing the major approach at the intersection. This is similar to what exist around the world, including the developed and developing ones, due to the fact that traffic accident causes vast damages to the economy and community. The study has therefore exposed the relationship between the traffic conflict and traffic volume and also help us to understand the potential collision or accident crashes at the study intersection.

\section{REFERENCES}

[1] C. J Baguley, C.J." The British Traffic Conflict Technique" Transport and Road Research Laboratory, NATO ASI Series, Vol F5, International Calibration Study of Traffic Conflict Techniques, 1984.

[2] WHO "Global status report on road safety 2015", World Health Organization.

[3] J .C. Glennon, W. D. Glaus, M .C. Sharp, and B .A. Thorson "Critique of the Traffic-conflict Technique". Transportation Research Record 630, Washington, D.C.: Transportation Research Board, 1977.

[4] M. Idris "Research and Development on the Application of Road Safety Technology" (Penelitian dan Pengembangan Aplikasi Teknologi Keselamatan Jalan). Final Report, 2006

[5] M. Mallah "Development of a Conflict Rate Prediction Model at Unsignalized Intersection". University of South Florida. 2009.

[6] Guido, G., et al. Safety performance measures: a comparison between microsimulation and observational data, Procedia-Social and Behavioral Sciences, 20, 217-225, 2011

[7] Salamati, K., et al. Development and implementation of conflictbased assessment of pedestrian safety to evaluate accessibility of complex intersections, Transportation Research Record: Journal of the Transportation Research Board, 148-155. 2011.

[8] Zheng, L., Prevedouros, P. D. Traffic conflict techniques for road safety analysis: open questions and some insights, Canadian Journal of Civil Engineering, 41, 633-641.2014.

[9] P. Liu "Evaluation of the Operational Effects of U-Turn Movement". University of South Florida, 2006.

[10] M. R. Parker, and C. V. Zegeer, "Traffic Conflict Techniques for Safety and Operations: Engineers Guide". FHWA-IP-88-026. Washington, D.C., 1989a.

[11] P. C. Box and J.C. Oppenlander "Manual of Traffic Engineering Studies". Fourth Edition. Institute of Transportation Engineers, pgs 66 $-76.1976$.

[12] F. Pirinccioglu "Safety Impacts of Right Turns Followed by UTurns". University of South Florida, 2008.

[13] H. Kennedy "Unsignalized Intersection Collisions". NCHRP Report 500, Washington, D.C, Transportation Research Board, Spring 2006. 